\title{
Concomitant multi-vessel disease is associated with a lower procedural death rate in patients treated with percutaneous coronary interventions within the left main coronary artery (from the ORPKI registry)
}

Rafał Januszek ${ }^{1}$, Artur Dziewierz ${ }^{2,3}$, Zbigniew Siudak', Tomasz Rakowski ${ }^{2,3}$, Tomasz Kameczura ${ }^{5}$, Tomasz Tokarek², Dariusz Dudek ${ }^{2,3,6}$, Stanisław Bartuś ${ }^{2,3}$

\begin{abstract}
${ }^{1}$ Department of Clinical Rehabilitation, University of Physical Education, Krakow, Poland

${ }^{2} 2^{\text {nd }}$ Department of Cardiology and Cardiovascular Interventions, University Hospital, Krakow, Poland

${ }^{3} 2^{\text {nd }}$ Department of Cardiology, Jagiellonian University Medical College, Krakow, Poland ${ }^{4}$ Faculty of Medicine and Health Sciences, Jan Kochanowski University, Kielce, Poland ${ }^{5}$ Chair of Electroradiology, Faculty of Medicine, University of Rzeszow, Rzeszow, Poland ${ }^{6}$ Department of Interventional Cardiology, Jagiellonian University Medical College, Krakow, Poland
\end{abstract}

Submitted: 7 April 2018; Accepted: 11 June 2018

Online publication: 22 June 2019

Arch Med Sci 2021; 17 (4): 881-890

DOI: https://doi.org/10.5114/aoms.2019.82666

Copyright (c) 2019 Termedia \& Banach

\section{Abstract}

Introduction: In this study, we aimed to distinguish differences in the procedural complication rate in a group of patients undergoing percutaneous coronary interventions $(\mathrm{PCI})$ of the left main coronary artery (LMCA) between patients with isolated LMCA disease and multi-vessel disease (MVD) with LMCA involvement and to identify their predictors.

Material and methods: We assessed 221,187 patients from the Polish Cardiovascular Intervention Society national registry (ORPKI) regarding all $\mathrm{PCl}$ procedures performed in Poland in 2015 and 2016. We extracted data of 1,819 patients with isolated LMCA disease and 3,718 patients with MVD and LMCA involvement. We compared those two groups in terms of procedural complications and their predictors.

Results: The overall rate of procedural complications was significantly higher in patients treated with LMCA PCI both in the group of patients with isolated LMCA (6.5\%) and the group with MVD with LMCA involvement (7.3\%) compared to the non-LMCA PCI group (1.9\%, $p=0.002)$. Multivariate analysis confirmed that MVD with LMCA involvement is an independent predictor of decreased risk of procedural death in the overall group of patients undergoing $\mathrm{PCI}$ of the LMCA (odds ratio: 0.583 ; $95 \%$ confidence interval: $0.4-0.848 ; p=0.005)$.

Conclusions: The MVD involvement in patients treated with $\mathrm{PCI}$ of the LMCA may play a protective role. Patients with isolated LMCA involvement undergoing $\mathrm{PCl}$ should be subjected to special care and protected by various methods, such as devices to support left ventricle function.

Key words: percutaneous coronary interventions, left main coronary artery, multi-vessel disease, procedural complications, mortality.

\author{
Corresponding author: \\ Stanisław Bartuś MD, PhD \\ $2^{\text {nd }}$ Department \\ of Cardiology and \\ Cardiovascular Interventions \\ University Hospital \\ 17 Kopernika St \\ 31-501 Krakow, Poland \\ Phone: +48 124247170 \\ Fax: +48 124247180 \\ E-mail: stanisław.bartus@ \\ uj.edu.pl
}




\section{Introduction}

Since 1962, the leading method of coronary artery disease (CAD) treatment has been coronary artery bypass grafting (CABG). Nowadays, due to the introduction of percutaneous coronary interventions $(\mathrm{PCl})$ in 1977, the number and type of indications for $\mathrm{PCl}$ have been constantly increasing. The optimal revascularization strategy for patients with multi-vessel disease (MVD) and left-main coronary artery disease (LMCA) is a continuing topic of debate [1]. Percutaneous coronary interventions of the LMCA is associated with high morbidity and mortality due to the large amount of myocardium at risk. European and U.S. guidelines recommend that most patients with LMCA disease should be treated with CABG $[2,3]$. Despite significant developments in $\mathrm{PCl}, \mathrm{CABG}$ remains the most commonly used treatment option for patients with complex CAD and those who are high-risk [4]. However, randomized trials have suggested that PCls with drug-eluting stents (DESs) may be an acceptable alternative for selected patients with LMCA disease [5-7]. Moreover, new $\mathrm{PCl}$ devices including newer stent generations improve procedural and clinical outcomes in patients undergoing $\mathrm{PCl}$ and are related to a lower rate of procedural complications $[8,9]$. Nonetheless, the group of patients undergoing PCI of the LMCA is not homogeneous, which undoubtedly has an impact on the procedural outcomes.

Therefore, the aim of the current study was to identify the differences in procedural complications between the groups of patients with isolated LMCA disease and MVD with LMCA involvement undergoing $\mathrm{PCl}$ of the LMCA and to identify their potential predictors.

\section{Material and methods}

\section{Study population, design and definitions}

Data for all patients who underwent $\mathrm{PCl}$ in Poland between January 2015 and December 2016 were analyzed. Prospectively collected data on PCI practice in Poland were obtained from the ORPKI Polish National Dataset, which is coordinated nationwide by the Jagiellonian University Medical College in cooperation with AISN PTK (Association of Cardiovascular Interventions, Polish Cardiac Society). Database characteristics and data collection methods have been included in previously published articles [10-13]. Patients were categorized according to whether they were diagnosed with isolated LMCA disease and PCI of the LMCA or MVD with LMCA involvement and $\mathrm{PCl}$ of the LMCA. In general, MVD was defined as a disease stage in which at least two or three of the epicardial coronary arteries are affected by atherosclerosis of significant severity. Significant stenosis of the LMCA in coronary angiography was considered as $>50 \%$, while in the case of the other coronary arteries, it was $>70 \%$ or $>50 \%$ when in-stent restenosis was implemented. When the significance of stenosis was not obvious in regular coronary angiography, intravascular ultrasound (IVUS) and/or fractional-flow reserve assessment was performed for confirmation or exclusion. All indices recorded in the ORPKI database are based on procedural data uploaded by the operator after each procedure. Therefore, they do not include all in-hospital complications, mainly those which occurred after the procedure until discharge from the hospital. Procedural complications include those occurring in the catheterization laboratory and were found by an interventional cardiologist who performed angioplasty and described them in an ORPKI protocol of the procedure drawn up after the patient was transferred from the operating room to the ward. Also, we have not collected follow-up data after discharge due to lack of patient IDs. The decision to perform PCI of the LMCA in isolated LMCA disease and $\mathrm{PCl}$ in patients with MVD and LMCA involvement was at the operators' discretion at each center according to current guidelines, and it was preceded by a heart team council deliberation [3]. All clinical decisions, such as vascular access, thrombectomy, treatment with glycoprotein (GP) Ilb/IIla inhibitors or bivalirudin, were at the operators' discretion. The definition of procedural complications including death, perforation, dissection, myocardial infarction (MI), allergic reaction, cerebral stroke, puncture site bleeding, no-reflow or cardiac arrest remained according to the operators' personal preferences and knowledge [10]. Cardiac arrests were reported in patients who survived, whereas those who died after cardiac arrest were reported as procedural deaths. For patients who have undergone so-called protected LMCA PCI, we found patients who underwent CABG surgery in the past in both compared groups.

\section{Multifactorial analysis}

We concentrated our analysis on the comparison of procedural complications between the groups of patients with isolated LMCA disease and MVD with LMCA involvement undergoing PCI. Due to the fact that the only significant difference was observed for the death and arterial dissection rates, the number of individuals was relatively low in both investigated groups compared to the death rate; however, we managed to identify its predictors in univariate and multivariable analysis. In this analysis, the following variables were tested in the overall group of patients undergoing $\mathrm{PCl}$ of the LMCA: age, gender, diabetes, previous cerebral stroke, myocardial infarction, previous $\mathrm{PCl}$ 
and $\mathrm{CABG}$, smoking status, concomitant diseases including psoriasis, hypertension, kidney disease, chronic obstructive pulmonary disease, clinical presentation of coronary artery disease at baseline (stable angina (SA) vs. acute coronary syndrome (ACS), SA vs. acute myocardial infarction (AMI), SA vs. unstable angina (UA), UA vs. AMI), pharmacological treatment before $\mathrm{PCl}$ and during $\mathrm{PCl}$ (acetylsalicylic acid (ASA), unfractionated heparin (UFH), low-molecular weight heparin (LMWH), P2Y12 inhibitors, thrombolysis, GP IIb/IIla inhibitors, bivalirudin), vascular access (radial vs. femoral), use of additional diagnostic methods such as fractional flow reserve (FFR), IVUS, optical coherent tomography (OCT), thrombectomy, thrombolysis in myocardial infarction (TIMI) flow before and after $\mathrm{PCI}$, contrast dose and radiation exposure, $\mathrm{PCl}$ of chronic total occlusions or bifurcation, stent implantation, drug-eluting stent (DES) implantation, number of implanted DES stents (one vs. two or more stents), bare-metal stent (BMS) implantation, number of implanted stents regardless of type (one vs. two or more stents), bioresorbable scaffold (BRS) implantation and $\mathrm{PCl}$ with plain old balloon angioplasty (POBA) and/or failed $\mathrm{PCl}$. Forward selection with a probability value for covariates to enter the model was set at the level of 0.05 .

\section{Statistical analysis}

All continuous variables were evaluated with the Kolmogorov-Smirnov test for distribution. Continuous variables are presented as mean \pm standard deviation and median \pm interquartile range. Categorical variables are presented as numeric values and percentages. Continuous variables were compared using the two-tailed Student $t$-test and the Mann-Whitney $U$-test, whereas categorical variables were compared using the $\chi^{2}$ test. Also, Spearman's rank correlation coefficient was calculated for the assessment of the potential relationship between death rate and selected indices in the isolated LMCA group and the MVD group with LMCA involvement. Statistical significance was accepted at a 0.05 level of probability. The statistical analyses were performed using Statistica 10.0 software (Dell Software, Inc., Round Rock, TX, USA).

\section{Results}

\section{General characteristics}

The general characteristics of patients examined in the current study including concomitant diseases, smoking, previous cardiovascular procedures, gender and age in the isolated LMCA group and the MVD group with LMCA involvement are presented in Table I.

\section{Clinical presentation, vascular access and procedural variables}

We compared types of clinical presentation, vascular access and selected procedural indices which involved procedural contrast dose, radiation exposure, use of FFR, IVUS and OCT, type of the lesion undergoing $\mathrm{PCl}$ including chronic total occlusion (СTO), bifurcations and the use of addi-

Table I. Baseline characteristics

\begin{tabular}{|lccc|}
\hline Variables & \multicolumn{2}{c|}{ LMCA PCI } & P-value \\
\cline { 2 - 3 } & Isolated LMCA & LMCA in MVD & 0.0003 \\
\hline Age [years] & $69.3 \pm 10.7$ & $70.4 \pm 10.6$ & $70(63-79)$ \\
\hline Gender, male & $69(62-78)$ & 0.37 \\
\hline Diabetes & $1,306(71.8)$ & $2,628(70.7)$ & 0.39 \\
\hline Hypertension & $495(27.2)$ & $1,052(28.3)$ & 0.02 \\
\hline Prior cerebral stroke & $1,257(69.1)$ & $2,677(72.0)$ & 0.24 \\
\hline Prior myocardial infarction & $83(4.6)$ & $197(5.3)$ & 0.21 \\
\hline Prior PCl & $694(38.1)$ & $1,483(39.9)$ & 0.06 \\
\hline Prior CABG & $738(40.6)$ & $1,410(37.9)$ & 0.63 \\
\hline Current smoker & $389(21.4)$ & $816(21.9)$ & 0.48 \\
\hline Kidney failure & $300(16.5)$ & $641(17.2)$ & 0.29 \\
\hline COPD & $172(9.4)$ & $385(10.3)$ & 0.54 \\
\hline
\end{tabular}

$C A B G$ - coronary artery bypass grafting, COPD - chronic obstructive pulmonary disease, LMCA - left main coronary artery, MI - myocardial infarction, MVD - multi-vessel disease, $P C l$ - percutaneous coronary intervention. Data given as $\pm S D$, interquartile range (lower quartileupper quartile) or number and percentages. P-values were calculated for continuous variables using the two-tailed Student $t$-test or the Mann-Whitney U-test whereas the $\chi^{2}$ test was used for categorical variables. 
Table II. Clinical presentation, vascular access and procedural variables

\begin{tabular}{|c|c|c|c|}
\hline \multirow[t]{2}{*}{ Variables } & \multicolumn{2}{|c|}{ LMCA PCI } & \multirow[t]{2}{*}{$P$-value } \\
\hline & Isolated LMCA & LMCA in MVD & \\
\hline \multicolumn{4}{|l|}{ Clinical presentation of CAD: } \\
\hline Stable angina & $519(28.6)$ & $918(24.7)$ & 0.002 \\
\hline Unstable angina & $644(35.4)$ & $1,198(32.2)$ & 0.02 \\
\hline NSTEMI & $345(19.0)$ & $883(23.7)$ & 0.0001 \\
\hline STEMI & $268(14.7)$ & $654(17.6)$ & 0.007 \\
\hline Others & $41(2.2)$ & $64(1.7)$ & 0.17 \\
\hline \multicolumn{4}{|l|}{ Vascular access: } \\
\hline Femoral artery & $717(39.4)$ & $1,575(42.4)$ & 0.03 \\
\hline Left radial artery & $325(17.9)$ & $588(15.8)$ & 0.05 \\
\hline Right radial artery & $748(41.1)$ & $1,501(40.4)$ & 0.59 \\
\hline Other & $29(1.6)$ & $54(1.4)$ & 0.68 \\
\hline Bifurcation & $203(11.1)$ & $607(16.3)$ & 0.0004 \\
\hline Chronic total occlusion & $10(0.5)$ & $78(2.1)$ & $<0.0001$ \\
\hline Fractional flow reserve & $22(1.2)$ & $50(1.3)$ & 0.67 \\
\hline Intravascular ultrasound & $173(9.5)$ & $300(8.1)$ & 0.07 \\
\hline Optical coherence tomography & $5(0.3)$ & $13(0.3)$ & 0.64 \\
\hline Rotablation & $19(1.0)$ & $60(1.6)$ & 0.09 \\
\hline Thrombectomy & $33(1.8)$ & $67(1.8)$ & 0.97 \\
\hline Contrast [ml] & $\begin{array}{c}186.8 \pm 81.4 \\
180(140-220)\end{array}$ & $\begin{array}{c}239.2 \pm 100 \\
220(180-300)\end{array}$ & $<0.001$ \\
\hline
\end{tabular}

CAD - coronary artery disease, LMCA - left main coronary artery disease, MVD - multi-vessel disease, NSTEMI-non-ST-segment elevation myocardial infarction, STEMI - ST-segment elevation myocardial infarction. Data given as $\pm S D$, interquartile range (lower quartile-upper quartile) or number and percentages. P-values were calculated for continuous variables using the two-tailed Student $t$-test or the MannWhitney $U$-test whereas the $\chi^{2}$ test was used for categorical variables.

tional devices such as rotablation or thrombectomy in two separate groups of patients: the isolated LMCA group and the MVD with LMCA involvement group. This is presented in Table II. The PCI of CTO lesions was recorded in patients after CABG surgery, which was usually performed many years ago, and where the critical stenosis of the LMCA over the years became chronic total occlusion. In the group of patients with isolated LMCA the number was 10 patients $(0.5 \%$ of all patients in this group and $2.57 \%$ of those with protected $\mathrm{PCl}$ of isolated LMCA disease), whereas in the group of patients with MVD and LMCA involvement, there were 78 patients $(2.1 \%$ of all patients in this group and $9.2 \%$ of those with protected PCI of LMCA disease in MVD patients). In both cases, the percentage of patients with CTO treated with $\mathrm{PCl}$ differed statistically significantly between the group of patients with isolated LMCA disease and the group of patients with MVD and LMCA involvement. This is presented in Tables I and II.

\section{Culprit lesion characteristics and type of $\mathrm{PCI}$}

We also distinguished and compared the type and frequency of culprit lesion undergoing $\mathrm{PCl}$ in three selected groups of patients, including de-novo, restenosis and in-stent thrombosis rates (Figure $1 \mathrm{~A}$ ). The restenosis rate was also divided into BMS, DES, BRS and POBA restenosis. This is presented in Figure $1 \mathrm{~A}$. The frequency of de-novo lesions was similar in the MVD group with LMCA involvement as compared to the isolated LMCA group, and was significantly higher in the MVD group with LMCA involvement compared to the non-LMCA PCI group ( $p<0.001)$. Also, the rate of restenosis was similar in both investigated groups of patients. This was mainly driven by a significantly higher rate of BMS in-stent restenosis $(p=0.005)$. In-stent thrombosis rates were lower in the MVD group with LMCA involvement compared to the isolated LMCA group $(0.2 \%$ vs. $0.4 \%$; $p=0.09)$. The location of significant stenosis in all patients in the isolated LMCA disease group was lo- 
A

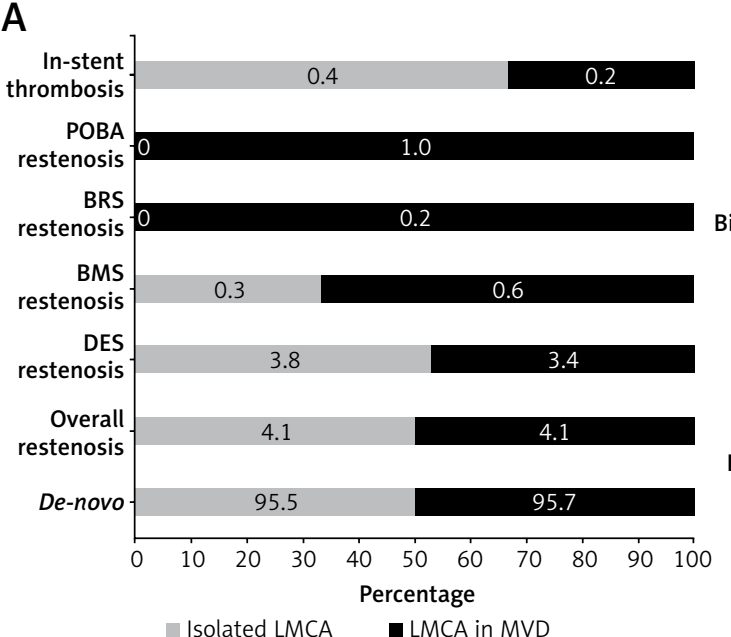

B

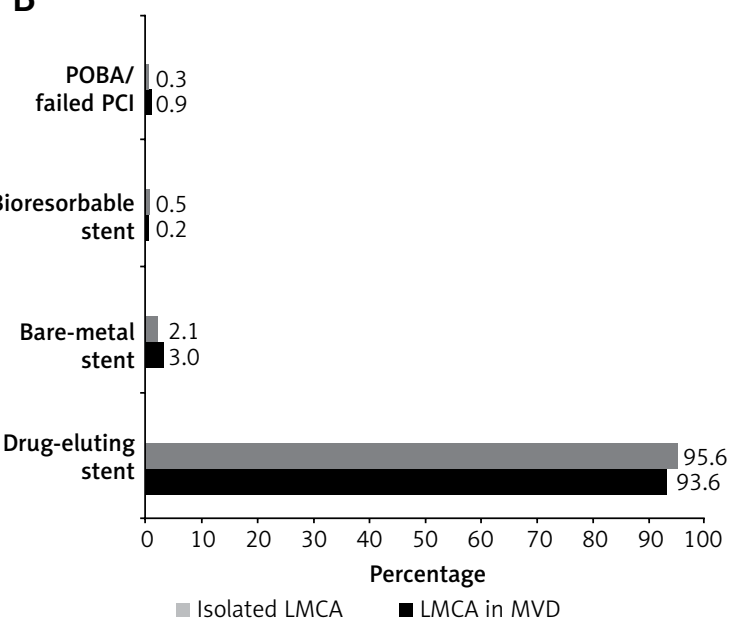

C

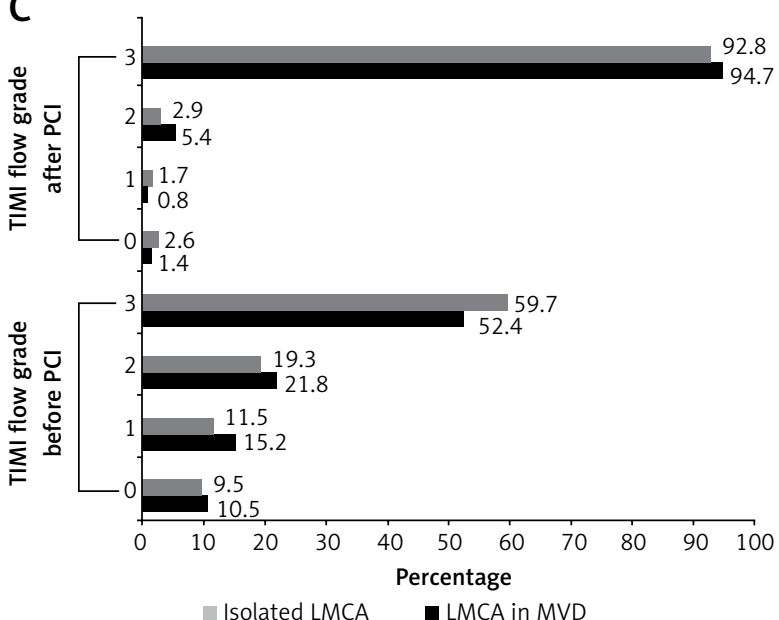

Figure 1. A - Lesion type before $\mathrm{PCl}$ in the isolated LMCA group and MVD group with LMCA involvement. B - Type of $\mathrm{PCl}$ in the isolated LMCA group and MVD group with LMCA involvement. $\mathrm{C}$ - TIMI flow grade before and after $\mathrm{PCl}$ in the isolated LMCA group and MVD group with LMCA involvement

BMS - bare-metal stent, BRS - bioresorbable scaffold, DES - drug-eluting stent, LMCA - left main coronary artery, MVD - multi-vessel disease, POBA - plain old balloon angioplasty, $P C l$ - percutaneous coronary intervention.

cated a priori in the LMCA. In the group of patients with MVD with LMCA involvement, significant stenosis was located in the LMCA in 3,440 (92.5\%) patients, in the proximal segment of the circumflex branch (Cx) in 1,366 (36.8\%) patients, in the proximal segment of the left anterior descending (LAD) branch in 1,695 (45.6\%) patients and in the intermediate artery in 116 (3.1\%) patients.

In the MVD group with LMCA involvement, $\mathrm{PCl}$ with no stent implantation was performed in $82(2.2 \%)$ patients, one stent in 1,133 (30.5\%) patients, two stents in $1,702(45.8 \%)$ patients and three or more stents were implanted in 801 $(21.5 \%)$ patients. Percutaneous coronary interventions of isolated LMCA disease was performed without stent implantation in 167 (9.2\%) patients, with one stent implantation in 1,618 (88.9\%) patients, with two stents in $29(1.6 \%)$ patients and three stents in $5(0.3 \%)$ patients. The DES stents were significantly more often implanted in the isolated LMCA group as compared to the MVD group with LMCA involvement $(p=0.002)$. The BMSs were more often implanted in the MVD with LMCA involvement group, but without statistical significance $(2.1 \%$ vs. $3 \%, p=0.052)$. There were few im- plantations of BRS stents in patients treated with $\mathrm{PCl}$ of the LMCA, while PCls with a drug-coating balloon were performed at similar rates ( $2 \%$ vs. $2.4 \%, p=0.43)$. This is presented in Figure $1 \mathrm{~B}$. While in the group of patients with isolated LMCA disease $\mathrm{PCl}$ of the LMCA did not coincide with $\mathrm{PCI}$ of other coronary artery or bypass, in the group of patients with MVD and LMCA involvement, $\mathrm{PCI}$ of the LMCA was accompanied by PCI of the RCA in $158(4.2 \%)$ patients, the $\mathrm{Cx}$ branch in a location other than the proximal segment in 347 (9.3\%) patients, the LAD branch in a location other than the proximal segment in 585 (15.7\%) patients, a saphenous graft in $14(0.4 \%)$ patients and the internal mammary artery in $4(0.1 \%)$ patients. In total, in addition to LMCA PCl, one or more PCls at one time were performed in 1,021 (27.4\%) patients, of which one additional PCI was performed in 940 patients, two in 75 patients and three in 6 patients. Bifurcations in the MVD group with LMCA involvement were treated without stent implantation in 24 (3.9\%) patients, with one stent $\mathrm{PCl}$ in $132(21.7 \%)$ patients, two stents in 277 (45.6\%) patients, three stents in $132(21.7 \%)$ patients and with four stents in 10 (1.6\%) patients. In the group 
of patients with isolated LMCA involvement, $\mathrm{PCl}$ of bifurcations was performed without stent implantation in 14 (6.9\%) patients, with one stent implantation in $165(81.3 \%)$ patients and with two stents in 24 (11.8\%) patients.

\section{Procedural effectiveness}

The percentage of patients with TIMI 3 flow grade was greater at baseline in the isolated LMCA group as compared to the MVD group with LMCA involvement $(p<0.001)$, while being significantly lower in patients with TIMI $1(p<0.001)$ and 2 flow grade $(p=0.03)$. The effectiveness of $\mathrm{PCl}$ assessed as post-procedural TIMI 3 flow grade was significantly higher in the MVD group with LMCA involvement compared to the isolated LMCA group $(94.7 \%$ vs. $92.8 \%, p=0.004)$. This is presented in Figure $1 \mathrm{C}$.

\section{Procedural complications}

The rate of overall procedural complications was similar in patients undergoing $\mathrm{PCl}$ of isolated LMCA compared to those with MVD with LMCA involvement. The death rate was significantly higher in the isolated LMCA group compared to the MVD group with LMCA involvement $(4.7 \%$ vs. $3 \%$, $p=0.002)$. This is presented in Figure 2 .

\section{Death rate and its relationship with selected indices}

The relationship between selected indices and the rate of death in the investigated groups of patients is presented in Table III. The death rate was significantly increased in older patients, females and those with diabetes in the MVD with LMCA involvement group of patients, while in the isolated LMCA group, it lost its significance.

\section{Predictors of procedural death}

Among the independent increased risk predictors of procedural death in the overall group of patients undergoing $\mathrm{PCl}$ of LMCA, we were able to confirm age $(p=0.04)$, diabetes $(p=0.04)$, previous cerebral stroke $(p=0.003), \mathrm{ACS}$ at $\mathrm{PCI}$ $(p=0.001)$, femoral access $(p=0.01)$, cardiogenic shock at $\mathrm{PCI}(p<0.001)$, and TIMI flow other than grade 3 after $\mathrm{PCI}(p<0.001)$ using multivariable analysis. We noted previous $\mathrm{PCI}(p=0.006)$, previous CABG $(p<0.001)$, and PCI of the LMCA in the LMCA group of patients with MVD involvement $(p<0.001)$ among the factors decreasing the risk of procedural death. This is presented in Figure 3.

\section{Discussion}

The present study revealed that the death rate in patients treated with $\mathrm{PCl}$ of the LMCA was significantly higher in patients with isolated LMCA disease compared to patients with LMCA involvement in MVD. It was also confirmed in multifactorial analysis that MVD is an independent protector from death in comparison to isolated LMCA disease.

The increased rate of procedural complications in patients undergoing $\mathrm{PCl}$ of the LMCA is conditioned by several factors, including a large area of the myocardium that is supplied by the LMCA and which is mainly responsible for the generation of the left ventricle ejection fraction, LMCA anatomy including its diameter and type of division [14-16]. It is difficult to compare the procedural complications and mortality rates in patients undergoing $\mathrm{PCl}$ of the LMCA because the availability of such data, apart from the designed trials, is limited. In the current study, the rate of procedural deaths in the analyzed population seems to be higher when

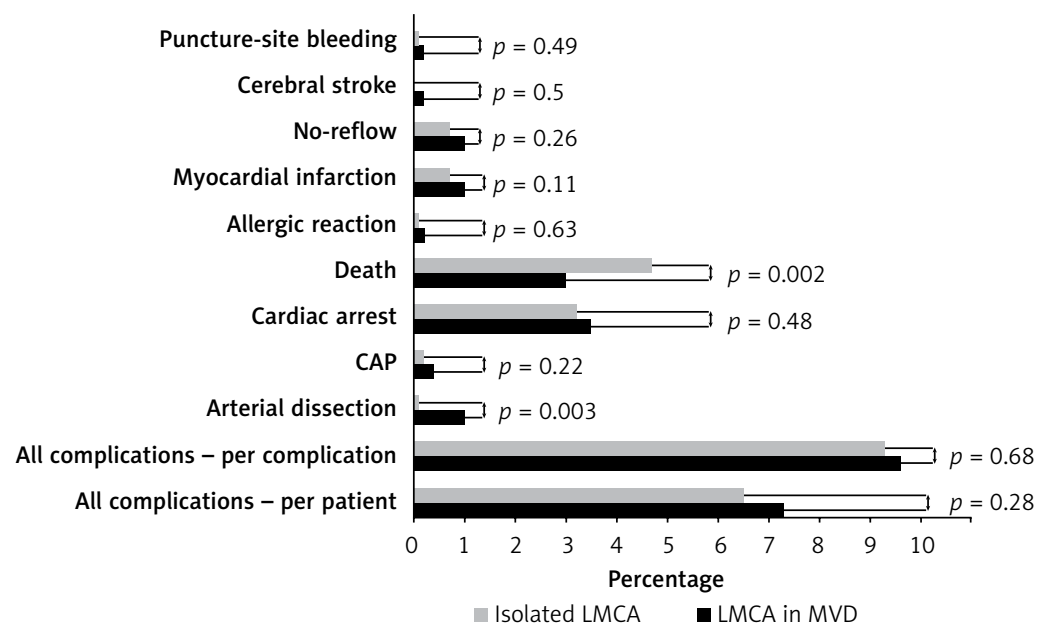

Figure 2. Procedural complication rates in the group of patients with isolated LMCA disease and MVD group with LMCA involvement

$C A P$ - coronary artery perforation, $L M C A$ - left main coronary artery, MVD - multi-vessel disease. 
Concomitant multi-vessel disease is associated with a lower procedural death rate in patients treated with percutaneous coronary interventions within the left main coronary artery (from the ORPKI registry)

Table III. Relationship between death rate and selected indices

\begin{tabular}{|c|c|c|c|c|}
\hline \multirow[t]{3}{*}{ Variables } & \multicolumn{4}{|c|}{ LMCA PCI } \\
\hline & \multicolumn{2}{|c|}{ Isolated LMCA } & \multicolumn{2}{|c|}{ LMCA in MVD } \\
\hline & $r$ & $P$-value & $r$ & $P$-value \\
\hline Age & 0.05 & 0.81 & 0.06 & $<0.001$ \\
\hline Gender, male & -0.03 & 0.21 & -0.03 & 0.03 \\
\hline Prior $C A B G$ & -0.1 & $<0.001$ & -0.07 & $<0.001$ \\
\hline Prior $\mathrm{PCl}$ & -0.11 & $<0.001$ & -0.08 & $<0.001$ \\
\hline Diabetes & -0.02 & 0.3 & 0.04 & 0.01 \\
\hline Kidney failure & 0.2 & 0.26 & 0.01 & 0.47 \\
\hline Stable angina vs. ACS & 0.13 & $<0.000$ & 0.09 & $<0.001$ \\
\hline Stable angina vs. AMI & 0.23 & $<0.001$ & 0.14 & $<0.001$ \\
\hline Drug eluting stent implantation $(+/-)$ & -0.17 & $<0.001$ & -0.14 & $<0.001$ \\
\hline $\mathrm{PCl}$ with stent implantation $(+/-)$ & -0.2 & $<0.001$ & -0.08 & $<0.001$ \\
\hline TIMI flow 0-1 vs. 2-3 before $\mathrm{PCl}$ & -0.26 & $<0.001$ & -0.11 & $<0.001$ \\
\hline IVUS vs. non-IVUS & -0.07 & 0.002 & -0.04 & 0.004 \\
\hline Femoral vs. radial access & 0.11 & $<0.001$ & 0.05 & 0.001 \\
\hline
\end{tabular}

ACS - acute coronary syndrome, AMI - acute myocardial infarction, CABG - coronary artery bypass graft operation, IVUS - intravascular ultrasound, MVD - multi-vessel disease, $\mathrm{PCl}$ - percutaneous coronary intervention, $\mathrm{TIMI}$ - thrombolysis in myocardial infarction. Data are given as Spearman's rank correlation coefficients and p-values. P-values were indicated using Spearman's rank correlation.

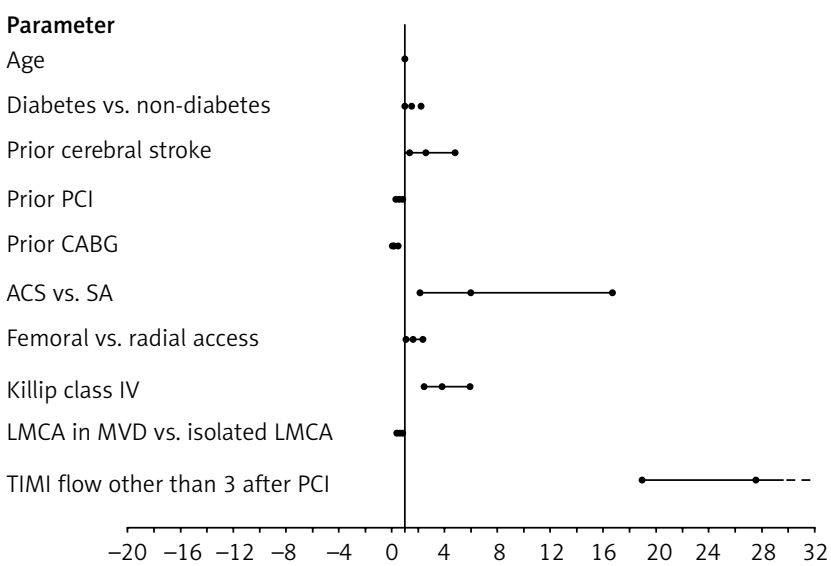

$\begin{array}{ccc}\text { OR } & 95 \% \mathrm{Cl} & P \text {-value } \\ 1.017 & 1.000-1.035 & 0.045 \\ 1.501 & 1.011-2.230 & 0.044 \\ 2.581 & 1.385-4.810 & 0.003 \\ 0.510 & 0.317-0.822 & 0.006 \\ 0.207 & 0.092-0.467 & <0.001 \\ 6.020 & 2.163-16.752 & 0.001 \\ 1.626 & 1.121-2.358 & 0.01 \\ 3.855 & 2.497-5.952 & <0.001 \\ 0.583 & 0.400-0.848 & 0.005 \\ 27.542 & 18.973-39.980 & <0.001\end{array}$

Figure 3. Predictors of death in the overall group of patients treated with LMCA PCI

ACS - acute coronary syndromes, CABG - coronary artery bypass grafting, LMCA - left main coronary artery, MVD - multi-vessel disease, $\mathrm{PCl}$ - percutaneous coronary intervention, $S A$ - stable angina.

compared to other randomized controlled trials (RCTs). This seems to be mostly driven by exclusion criteria. For example, the death rate of in-hospital or $<30$ days after the index procedure in patients with MVD undergoing $\mathrm{PCl}$ with everolimus-eluting stents or CABG was estimated at $0.6 \%$ in the $\mathrm{PCl}$ group and $1.1 \%$ in the CABG group, while after a mean follow-up of 2.9 years, the $\mathrm{PCl}$ death rate was $3.1 \%$ per year and after CABG surgery it was $2.9 \%$ per year [17]. Also, in another study performed in a group of patients with MVD undergoing revascularization ( $\mathrm{PCl}$ or $\mathrm{CABG}$ ) the 30-day mortality rate was $0.2 \%$ in the $\mathrm{PCI}$ group and $0.8 \%$ in the CABG group [18]. However, some of the published studies reported comparable mortality in a similar group of patients [19]. Valgimigli et al. compared the effects of LMCA stenting according to the type of implanted stent (BMS vs. DES). Their population included a similar percentage of patients with protected LMCA stenosis $-22 \%$ in the BMS group and $16 \%$ in the DES group. They included elective and non-elective patients qualified for $\mathrm{PCl}$ and the 30-day death rate was $7 \%$ for BMS stents and $11 \%$ for the DES group [19]. On 
the other hand, the meta-analysis performed by Pandya et al. reported the mortality rate of $5.94 \%$ after $\mathrm{PCl}$ of the unprotected LMCA during the 612 months of follow-up after DES implantation, while BMS was at the level of $7.24 \%$.

However, we noted significantly higher mortality and lower coronary dissection rates in the group with isolated LMCA disease compared to the group of patients with LMCA involvement in MVD disease; multifactorial analysis confirmed only MVD as a predictor of decreased rate of death. The number of coronary dissections and its percentage in both groups was lower compared to the death rates, and this probably determined the lack of reflection in multifactorial analysis assessment. The higher dissection rate in the MVD group compared to the isolated LMCA group was probably mainly driven by higher rate of bifurcations, CTOs and PCls of arteries other than those linked to the LMCA. The protective effect of MVD on procedural mortality in patients undergoing $\mathrm{PCl}$ of the LMCA was probably due to the constant ischemic conditioning of heart muscle related to stenoses in other arteries in contrast to patients with isolated stenosis of the LMCA, where the heart muscle is definitely more often less used to ischemia. This has a substantial impact during the $\mathrm{PCl}$ procedure where the technique of the procedure requires periodic occlusion of the left coronary artery. Interestingly, against this thesis, it is justified by the fact that the frequency and proportion of non-death related cardiac arrests were similar in the group of patients with isolated LMCA disease and those with MVD and LMCA involvement. Also, the procedural death rate was undoubtedly significantly influenced by the higher percentage of post-procedural TIMI 3 flow grade in the group of patients with $\mathrm{PCl}$ of the LMCA in MVD. Additionally, residual stenosis, which was not assessed in the current study, could influence this relationship. However, the incidence of diabetes and kidney failure did not differ significantly between the two investigated groups. Considering the effect of peripheral circulation on procedural complications and angiographic outcomes, bypasses should first be deliberated. The percentage of patients after the CABG procedure was similar in both groups. It can therefore be hesitantly concluded that collateral circulation supplied by bypasses had a significant impact on procedural outcomes. On the other hand, collateral circulation supplied by native arteries could have a greater contribution. In the group of patients with isolated LMCA disease, the collateral circulation was supplied by the right coronary artery (RCA) in many cases due to the fact that RCAs were patent in all cases in this group and free of critical stenoses. We are also not in possession of data on the CABG patency, possible CTOs and collateral supply in the LM territory of the MVD patients, except for raw data on the percentage of patients after CABG. This was not the case for all patients in the MVD group with LMCA involvement where, in many cases, the RCA was critically stenosed or totally occluded. However, we do not have accurate data to determine the number of patients in whom this occurred. Nevertheless, it seems that this mechanism should have an impact on improving the results in the group of patients with isolated LMCA involvement, in comparison to the MVD group of patients with LMCA involvement.

Among the common predictors of mortality we may find previous CABG, previous cerebral stroke, ACS, femoral access, cardiogenic shock and post-procedural TIMI 3 flow grade. It was demonstrated that patients after transient ischemic attack and ischemic stroke are at increased risk of myocardial infarction and non-stroke vascular death [20]. This was confirmed in the present study among the overall group of patients treated with LMCA PCI. This is probably due to poorer mobility of those patients and the limited response of the cardiovascular system to stress such as $\mathrm{PCl}$ of the LMCA. This response includes, among others, vasoreactivity, thrombogenicity, sympathetic stimulation and transient ischemia of heart muscle.

It has been proven that femoral access is associated with poorer clinical outcomes in patients with ACS treated using $\mathrm{PCl}$ [21]. This could be explained mostly by the fact that patients with femoral access are often in a severe clinical state and undergo more complicated and demanding procedures.

In the current study, procedural success expressed as TIMI flow 3 grade after $\mathrm{PCI}$ was found to be an independent protecting factor of procedural deaths in the overall group of patients treated with $\mathrm{PCl}$ of the LMCA. This was especially expressed in the MVD group. This relationship seems to raise no doubts or discussion due to the fact that the successful procedure is assumed to be burdened with a smaller amount of procedural complications and mortality.

Acute coronary syndromes, cardiogenic shock before $\mathrm{PCl}$ and cardiac arrest during $\mathrm{PCl}$ are all clinical states which are related to increased risk of procedural complications and mortality, which has been proven in several published studies [22]. Patients with LMCA stenosis are at increased risk of cardiac arrest or cardiogenic shock due to several mechanisms discussed above.

In the analyzed study, the history of previous CABG was found to be an independent predictor of decreased risk of procedural death in all analyzed groups of patients treated with $\mathrm{PCl}$ of the LMCA. The percentage of patients after previous CABG was similar in the group of patients with MVD and LMCA involvement and isolated LMCA 
disease. Previously implanted grafts may serve as protection against transient ischemia during $\mathrm{PCl}$ of the LMCA, and due to that fact, could modify the rate and type of procedural complications. However, as mentioned above, the number of patent grafts is not without significance in the final analysis.

In the current study, kidney failure was not related to the death rate in the overall group of patients treated with $\mathrm{PCl}$ of the LMCA. Multivariate analysis also did not confirm this relationship in the group of patients treated with PCI of the LMCA. Previously published studies revealed that elevated creatinine level was associated with poor myocardial blood flow and with an increased risk of death during the one-year follow-up after emergency PCI procedures in patients with STEMI [23]. A similar relationship was found for diabetes [24, 25]. This relationship could be explained mainly due to the pathogenesis of atherosclerosis and higher frequency of MVD in patients with kidney failure and diabetes compared to those without kidney function impairment [24, 25].

In conclusion, $\mathrm{PCl}$ of the LMCA in patients with isolated LMCA disease is associated with increased risk of procedural mortality in comparison to patients with MVD and LMCA involvement. Based on the presented results, more caution in patients with isolated LMCA involvement treated with $\mathrm{PCl}$ is advised when considering a range of protective devices and strategies such as those for assisting the left ventricle ejection fraction.

First of all, this is a study based on the nationwide volunteer registry rather than a prospective randomized controlled trial. This tends to decrease and underestimate the detection of the procedural complication rate and other crucial variables which depend on subjective assessment of the operator, despite the large overall interventional volume included in our analysis. Furthermore, the current analysis does not include all in-hospital complications, which certainly weakens its value. Undoubtedly, the advantage of the current study is that the results are closer to real life than to randomized clinical trials and show clinical data depicting the results of LMCA PCIs in Central Europe. Comparison of groups in terms of the SYNTAX score could provide additional information about the predictors of procedural complications, although such analysis was impossible to perform due to the lack of such data. We also were not in possession of data regarding left ventricular function and number of patients transferred to CABG in urgent mode. The use of left ventricle assistance devices including pumps to support $\mathrm{PCl}$ procedures is very occasional in Poland and would certainly not have a significant impact on the results of the current study, while the use of intra-aortic balloons (IABP) is much more frequent, but also, data on the IABP placement were not included in the analyzed database. The frequency of IABP use can certainly be related to the frequency of procedural complications and angiographic effectiveness.

We also did not have accurate data on the type of technique used during the LMCA PCI procedure in individual groups of patients, such as whether proximal optimization technique or kissing balloons were used, or what kind of stenting technique for bifurcation was used, and what pressures were implemented when stents or balloons were inflated, and such a comparison would provide additional and more precise information.

\section{Conflict of interest}

The authors declare no conflict of interest.

\section{References}

1. Morice MC, Serruys PW, Kappetein AP, et al. Five-year outcomes in patients with left main disease treated with either percutaneous coronary intervention or coronary artery bypass grafting in the synergy between percutaneous coronary intervention with taxus and cardiac surgery trial. Circulation 2014; 129: 2388-94.

2. Fihn SD, Blankenship JC, Alexander KP, et al. 2014 ACC/ AHA/AATS/PCNA/SCAI/STS focused update of the guideline for the diagnosis and management of patients with stable ischemic heart disease: a report of the American College of Cardiology/American Heart Association Task Force on Practice Guidelines, and the American Association for Thoracic Surgery, Preventive Cardiovascular Nurses Association, Society for Cardiovascular Angiography and Interventions, and Society of Thoracic Surgeons. J Am Coll Cardiol 2014; 64: 1929-49.

3. Authors/Task Force members, Windecker S, Kolh P, Alfonso F, et al. 2014 ESC/EACTS Guidelines on Myocardial rEvascularization: The Task Force on Myocardial Revascularization of the European Society of Cardiology (ESC) and the European Association for Cardio-Thoracic Surgery (EACTS) Developed with the Special Contribution of the European Association of Percutaneous Cardiovascular Interventions (EAPCI). Eur Heart J 2014; 35: 2541-619.

4. Serruys PW, Morice MC, Kappetein AP, et al.; SYNTAX Investigators. Percutaneous coronary intervention versus coronary-artery bypass grafting for severe coronary artery disease. N Engl J Med 2009; 360: 961-72.

5. Capodanno D, Stone GW, Morice MC, et al. Percutaneous coronary intervention versus coronary artery bypass graft surgery in left main coronary artery disease: a meta-analysis of randomized clinical data. J Am Coll Cardiol 2011; 58: 1426-32.

6. Morice MC, Serruys PW, Kappetein AP, et al. Five-year outcomes in patients with left main disease treated with either percutaneous coronary intervention or coronary artery bypass grafting in the synergy between percutaneous coronary intervention with taxus and cardiac surgery trial. Circulation 2014; 129: 2388-94.

7. Cavalcante R, Sotomi Y, Lee CW, et al. Outcomes after percutaneous coronary intervention or bypass surgery in patients with unprotected left main disease. J Am Coll Cardiol 2016; 68: 999-1009.

8. Kaul U, Bangalore S, Seth A, et al.; TUXEDO-India Investigators. Paclitaxel-eluting versus everolimus-eluting 
coronary stents in diabetes. N Engl J Med 2015; 373 : 1709-19.

9. Sarno G, Lagerqvist B, Fröbert O, et al. Lower risk of stent thrombosis and restenosis with unrestricted use of 'new-generation' drug-eluting stents: a report from the nationwide Swedish Coronary Angiography and Angioplasty Registry (SCAAR). Eur Heart J 2012; 33: 606-13.

10. Januszek R, Siudak Z, Dziewierz A, et al. Predictors of in-hospital effectiveness and complications of rotational atherectomy (from the ORPKI Polish National Registry 2014-2016). Catheter Cardiovasc Interv 2018; 92 . E278-87.

11. Siudak Z, Tokarek T, Dziewierz A, et al. Reduced periprocedural mortality and bleeding rates of radial approach in ST-segment elevation myocardial infarction. Propensity score analysis of data from the ORPKI Polish National Registry. Eurolntervention 2017; 13: 843-50.

12. Januszek R, Dziewierz A, Siudak Z, et al. Chronic obstructive pulmonary disease and periprocedural complications in patients undergoing percutaneous coronary interventions. PLos One 2018; 13: e0204257.

13. Januszek RA, Dziewierz A, Siudak Z, et al. Diabetes and periprocedural outcomes in patients treated with rotablation during percutaneous coronary interventions. Cardiol J 2018; DOI: 10.5603/CJ.a2018.0102.

14. Zacharias T, Ferreira N. Nutritional risk screening 2002 and ASA score predict mortality after elective liver resection for malignancy. Arch Med Sci 2017; 13: 361-9.

15. Staszewski J, Piusińska-Macoch R, Brodacki B, Skrobowska E, Macek K, Stępień A. Vascular parkinsonism and vascular dementia are associated with an increased risk of vascular events or death. Arch Med Sci Atheroscler Dis 2017; 2: e16-23.

16. Biyik I, Uzun F, Erturk M, et al. Does contrast media volume affect long-term survival in patients with chronic kidney disease? Arch Med Sci Atheroscler Dis 2017; 2: e82-9.

17. Bangalore S, Guo Y, Samadashvili Z, et al. Everolimuseluting stents or bypass surgery for multivessel coronary disease. N Engl J Med 2015; 372: 1213-22.

18. Yang JH, Gwon HC, Cho SJ, et al. Comparison of coronary artery bypass grafting with drug-eluting stent implantation for the treatment of multivessel coronary artery disease. Ann Thorac Surg 2008; 85: 65-70.

19. Valgimigli M, van Mieghem CA, Ong AT, et al. Short- and long-term clinical outcome after drug-eluting stent implantation for the percutaneous treatment of left main coronary artery disease: insights from the rapamycin-eluting and taxus stent evaluated at Rotterdam Cardiology Hospital Registries (RESEARCH and T-SEARCH). Circulation 2005; 111: 1383-9.

20. Touzé E, Varenne O, Chatellier G, et al. Risk of myocardial infarction and vascular death after transient ischemic attack and ischemic stroke: a systematic review and meta-analysis. Stroke 2005; 36: 2748-55.

21. Kilic S, Hermanides RS, Ottervanger JP, et al.; Zwolle Myocardial Infarction Study Group. Effects of radial versus femoral artery access in patients with acute myocardial infarction: a large centre prospective registry. Neth Heart J 2017; 25: 33-9.

22. Halkin A, Singh M, Nikolsky E, et al. Prediction of mortality after primary percutaneous coronary intervention for acute myocardial infarction: the CADILLAC risk score. J Am Coll Cardiol 2005; 45: 1397-405.

23. Zhao L, Wang L, Zhang Y. Elevated admission serum creatinine predicts poor myocardial blood flow and one-year mortality in ST-segment elevation myocardial infarction patients undergoing primary percutaneous coronary intervention. J Invasive Cardiol 2009; 21: 493-8.

24. De Luca G, Gibson CM, Bellandi F, et al. Diabetes mellitus is associated with distal embolization, impaired myocardial perfusion, and higher mortality in patients with ST-segment elevation myocardial infarction treated with primary angioplasty and glycoprotein IIb-IIla inhibitors. Atherosclerosis 2009; 207: 181-1.

25. Wang R, Mei B, Liao X, et al. Determination of risk factors affecting the in-hospital prognosis of patients with acute ST segment elevation myocardial infarction after percutaneous coronary intervention. BMC Cardiovasc Disord 2017; 17: 243 